\title{
EPAs methodology to inform TSCA pre-manufacturing notification decision-making: a critical analysis based on chemicals regulated by consent order
}

\section{Robert Borotkanics*}

Department of Environmental Health Sciences, Johns Hopkins Bloomberg School of Public Health, 615 N. Wolfe, St. Baltimore, Maryland, 21205, USA

and

Faculty of Medicine and Health Sciences,

Macquarie University, Australia

Email: rborotk1@jhu.edu

*Corresponding author

\section{Paul Locke}

Department of Environmental Health Sciences, Johns Hopkins Bloomberg School of Public Health, 615 N. Wolfe, St. Baltimore, Maryland, 21205, USA Email: plocke@jhu.edu

\begin{abstract}
Regulatory toxicology has emerged as a necessary discipline to ensure chemicals introduced into commerce are safe. The New Chemicals program is a regulatory toxicology program required under the Toxic Substances Control Act (TSCA) where the US Environmental Protection Agency (EPA) evaluates new or significant new uses of existing chemicals. Submitters are not required to include human or environmental effects data, or undertake toxicity testing and so constrain the EPA and the basic data available to make informed decisions. We therefore sought to determine the methodology used by this program to inform regulatory, consent order decisions. We found that the EPA applied analogue analyses, or in silico methods to inform two-thirds of the decisions evaluated. No new tests were carried out. This study's findings are important for other regulators in the potential adoption of alternative testing methods to inform regulatory decisions going forward.
\end{abstract}

Keywords: TSCA new chemicals program; alternative test methods; tiered testing strategy.

Reference to this paper should be made as follows: Borotkanics, R. and Locke, P. (2017) 'EPAs methodology to inform TSCA pre-manufacturing notification decision-making: a critical analysis based on chemicals regulated by consent order', Int. J. Risk Assessment and Management, Vol. 20, Nos. 1/2/3, pp.226-239. 
Biographical notes: Robert Borotkanics is a former National Institutes of Health Research Fellow and retains an interdisciplinary doctorate in biostatistics and toxicology along with Master's degrees in bioinformatics and epidemiology. His research interests are in the application of statistical and computational methods in toxicology for purposes of risk assessment and decision-making. He is presently a research fellow in applied biostatistics.

Paul Locke is an Associate Professor in the Department of Environmental Health Sciences at the Johns Hopkins Bloomberg School of Public Health. He holds a joint appointment in the Department of Health Policy and Management. $\mathrm{He}$ is also the Distinguished Visiting Professor of Animal Law and Science at the Northwestern School of Law of Lewis and Clark College. At Hopkins, he leads an integrated program that focuses on research-to-practice initiatives to better protect public health, especially in advancing evidence-based in vitro toxicology and radiation protection policy at federal and international organisations. He is admitted to practice law in the state of New York and the District of Columbia, the Southern District Court of New York and is a member of the bar of the US Supreme Court.

This paper is a revised and expanded version of a paper entitled 'Implementing toxicity testing in the 21 st century' presented at Health Canada Training Seminar on Risk Science in the 21st Century, University of Ottawa, Ottawa, Ontario, Canada, 4-6 March 2013.

\section{Introduction}

Regulatory toxicology has emerged as a necessary discipline to ensure chemicals introduced into commerce are safe. Contemporary history has taught us that while many chemicals are not harmful to the health of humans and the environment, many chemicals were also found after their introduction into commerce to cause harm. For instance, perfluoroalkylated substances are a group of fluorinated compounds with wide application, ranging from use in household products to outdoor clothing. Perfluorooctane sulfonate (PFOS) and perfluorooctanoic acid (PFOA) belong to this chemical class and have been in production since the 1940s. Evidence has shown over time that increased exposure to PFOS is associated with bladder cancer, and PFOA is associated with kidney and testicular cancers (Barry et al., 2013; Nakayama et al., 2005; Benbrahim-Tallaa et al., 2014).

In the USA, regulatory toxicology is guided by a number of laws. One of the major laws that control the introduction and use of chemicals in commerce is the Toxic Substances Control Act (TSCA, 1976). TSCA was enacted in 1976 and its chemicals in commerce provisions have not been amended since then. TSCA is implemented and administered by the US EPA. This law includes provisions for management of existing chemicals, introduction of new chemicals into commerce, along with reporting and record keeping requirements. An important component of the law and associated administration is the New Chemicals Program. The New Chemicals Program evaluates chemicals to be introduced into commerce and also significant new uses of existing chemicals.

EPA decision-making under TSCA is dependent upon the science of toxicology, of which an integral component is toxicity testing. Data from toxicity testing is routinely 
used by the EPA to evaluate the potential risks of chemicals and underpins regulatory decision making, including regulatory control strategies. However, in the case of TSCA and the review of new chemical substances, the entity submitting the premanufacture notification (PMN) to the EPA is not required to carry out toxicity testing nor to supply human or environmental effects data (TSCA, 1976; US Government Publishing Office, 2011). Further, if the PMN submitter volunteers a test result, they are not required to comply with any regulatory testing provisions. The data a PMN submitter is required to submit is minimal and is limited to the chemical's identity (name and chemical abstract service - CAS - registry number) and molecular structure (US Government Publishing Office, 2011). Further, the EPA, under TSCA, has only 90 days to review the PMN submission and complete their decision cycle, making it impractical to undertake various types of toxicity tests.

These statutory restrictions place considerable constraints on the EPA with respect to the basic data available to inform decisions. Little data and no human and environmental effects data is required to be submitted by PMN submitters; however, such information is needed to inform whether or not a chemical substance is or is not a human or environmental health risk.

In light of these statutory restrictions, we therefore sought to determine the data and methodologies used to inform regulatory decisions by the TSCA New Chemicals Program. We collected, evaluated and characterised the decisions that resulted in regulation of new chemicals via consent order. A consent order is a legally binding agreement that the PMN submitter enters into with the EPA. These orders specify regulatory parameters, for which the PMN submitter agrees to as part of the agreement to manufacture, distribute, import or dispose their chemical substance.

Our evaluation of these consent orders indicates that for the decisions evaluated in this study the TSCA New Chemicals Program decision-making process largely utilises a combination of analogue analyses and data generated using in silico methods.

\section{Methods and data}

Our analysis of data and methods used to inform TSCA decisions is limited to publicly available information on chemicals that underwent the regulatory review of EPAs New Chemicals Program. This study focused on those chemicals that underwent PMN review and were permitted to enter commerce and were still in commerce as of January 2014, regulated by consent order. Excluded from this study are chemicals that qualify for low volume exemptions, low release exemptions, test market exemptions and those chemicals used for research and development purposes. Also excluded are those chemicals whose identities and supporting information are registered as confidential business information (CBI) by the PMN submitter, per section 14 of TSCA (1976).

The initial list of chemicals meeting inclusion criteria were first identified by the TSCA Chemical Substance, or 8(b), Inventory (Figure 1). The dataset was accessed February 4, 2014 and therefore includes all chemicals in commerce as of January 3, 2014. The EPA has 30 days to update the inventory based on notices of commencement of manufacture or import received from petitioners, post PMN review. The inventory specifies the generic name of the chemical, PMN number and whether or not the chemical is subject to a consent order. 
Figure 1 Inclusion criteria and documents sources for data abstraction

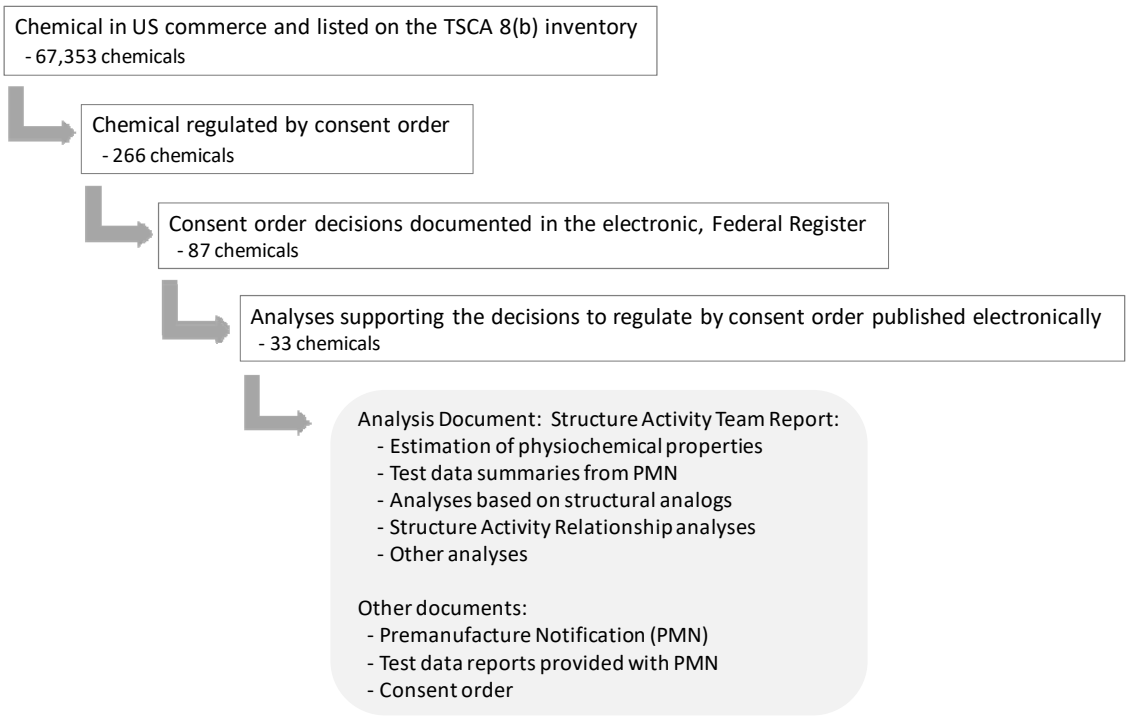

For this study, we were interested in the data and methods applied and used to inform the decisions to regulate new chemicals by consent order. We undertook to collect the documents supporting the consent order decisions and abstracted these documents for analysis. This information is communicated in three documents: Federal Register notices, Structure Activity Team (SAT) reports and the issued consent orders (Figure 1). The EPA is required under TSCA to announce their PMN regulatory decisions via the Federal Register. The Federal Register is a daily journal, established to communicate to the public the federal government's activities (Federal Register Act, 1935). The Federal Register is available in electronic form from 1995 to the present; however, it can include decisions prior to this date. The SAT report is a technical, EPA document that summarises EPAs PMN health and environmental health analyses. The consent order is a legally binding agreement between the EPA and the PMN submitter. The EPA electronically posts the SAT reports and consent orders and they are available via Regulations.gov. This central repository has been in existence since 2003, but contains information prior to that date (Executive Order 12866 of September 30, 1993). We carried out a search of all PMN-based consent order decisions on EPAs TSCA Chemical Substance Inventory as communicated in the electronic form and recorded this data for inclusion into the study.

\subsection{Review of EPA new chemical review methodologies}

We found that the EPA uses a number of approaches to review and evaluate PMN submissions, summarised herein (Environmental Protection Agency, 1997). The New Chemicals Program can take basic information provided by the petitioner and estimate physiochemical properties of a given chemical (Environmental Protection Agency, 1997; Boethling et al., 2004). If, for example, a petitioner does not submit physical properties data, information which is widely known to be very inexpensive and quick for submitters to produce (Environmental Protection Agency, 1994), then the EPA must make estimates. 
This can include physiochemical data as basic as a chemical's melting point, vapour pressure or octanol-water partition coefficient (Environmental Protection Agency, 1997). This is in sharp contrast to EU reporting requirements, which have always called for submission of physical properties data (Auer et al., 1990; Walker, 2003). These tools have been shown to accurately estimate the parameters they quantify (Environmental Protection Agency, 1994). These in silico methods are in addition to the established, manual protocol for identifying measured physiochemical properties and analogues of PMN substances (Environmental Protection Agency, 1997). This physiochemical information can then be used to conduct structure activity relationship (SAR) analyses. EPA uses SAR to predict the toxicity to aquatic organisms (Reuschenbach et al., 2008; Environmental Protection Agency, 2007). These combined in silico methods have undergone independent, scientific review (Environmental Protection Agency, 1994; EUROPA, 2006; European Commission, 2003). Because of their widespread use and acceptance in decision-making, we reason that these in silico methods can be said to be accepted on the basis of their passage through review and usage over time.

The EPA also relies upon libraries of publicly available human health and environmental health effects information about chemicals that have previously undergone in vivo or in vitro tests. This information sometimes includes human epidemiological/ occupational health data. The EPA further retains confidential libraries of information on chemicals that have undergone testing, but the results of which are not available to the public, because the tested chemicals are listed as CBI. Using these libraries, EPA systematically identifies an analogue or analogues of a given PMN substance. As used in this study, the term 'analogue' means a similar or equivalent chemical (or chemicals) in terms of structure or properties. Available study data, in vivo and in vitro, of these analogues are then retrieved from the libraries. Information is then reviewed and evaluated in a group setting of experts to infer the health and environmental effects that could potentially arise from exposure to the PMN substance. For this study, we refer to this approach as 'analogue analysis'.

The PMN decision-making process results in a determination of the potential for human and/or environmental health risk end points. These determinations can be made based on any number of endpoints (such as risk of neurotoxicity, risk of aquatic toxicity, and risk of carcinogenicity). We reviewed these decisions from the information contained in the documents, as previously described (Figure 1), and abstracted the decisions for analysis (Figure 2).

Figure 2 Data abstraction steps

1 Basis for decision

- Determination of human and/or environmental health risk

- Health and/or environmental health risk concern

- Basis for concern

2 Method(s) used to inform decision

- Physiochemical properties estimates/measures

- SAR (chemical or analogue)

- Analogue search of existing studies

- Submitted test data (chemical or analogue)

- Test by type (i.e., acute oral, dermal, etc.) 


\section{Results}

As of January 2014, there were 67,253 chemicals listed on the TSCA Chemical Substance Inventory. A total of 266 of these chemical are subject to regulation by consent order. Of the 266 chemicals, 33 chemicals met inclusion criteria for this study (Figure 1 and Table 1). The PMN substances that met inclusion criteria were decided upon by the EPA from 1999 to 2012.

Table 1 Chemicals meeting inclusion criteria

\begin{tabular}{|c|c|c|c|}
\hline Number & $\begin{array}{l}\text { Premanufacturing } \\
\text { number }\end{array}$ & Generic name (as given in federal register) & $C A S \#$ \\
\hline 1 & P-00-0346 & Dialkyl hydroxybenzenealkanoic acid ester & CBI \\
\hline 2 & P-00-0368 & $\begin{array}{c}\text { Benzenesulfonamide, alkylphenylsubstitutedphenyl } \\
\text { substituted carbonyl- }\end{array}$ & CBI \\
\hline 3 & P-01-0470 & Ethoxylated alkylphenol sulfate, ammonium salt & CBI \\
\hline 4 & P-01-0595 & Tertiary amine salt of glycol succinate & CBI \\
\hline 5 & P-01-0918 & Isocyanate compound, modified with methoxysilane & CBI \\
\hline 6 & P-02-0382 & Alkylbenzene sulfonate & CBI \\
\hline 7 & P-04-0640 & Diisocyanate terminated polycarbodiimide & CBI \\
\hline 8 & P-04-0834 & HDI biuret, hydroxyethyl methacrylate prepolymer & CBI \\
\hline 9 & P-06-0153 & Iso-tridecanol & CBI \\
\hline 10 & P-06-0816 & $\begin{array}{l}\text { Modified reaction products of alkyl alcohol, halogenated } \\
\text { alkane, substituted epoxide, and amino compound }\end{array}$ & CBI \\
\hline 11 & P-07-0087 & Partially fluorinated condensation polymer & CBI \\
\hline 12 & P-07-0328 & $\begin{array}{c}\text { Phenol, 4-[(alkyl) } \\
\text { Phenyl [4-(phenylsubstituted)phenylsubstituted]methyl] } \\
-2,6 \text {-bis(1,1-dimethylethyl)- }\end{array}$ & CBI \\
\hline 13 & P-07-0537 & Alkanenitrile, bis(cyanoalkyl)amino & CBI \\
\hline 14 & P-09-0048 & $\begin{array}{c}\text { Alkylcarboxy polyester acrylate reaction products with } \\
\text { mixed metal oxides }\end{array}$ & CBI \\
\hline 15 & P-10-0060 & Partially fluorinated alcohol substituted glycols & CBI \\
\hline 16 & P-10-0367 & $\begin{array}{l}\text { Carbon black derived from the pyrolysis of rubber tire } \\
\text { shreds }\end{array}$ & CBI \\
\hline 17 & P-10-0470 & $\begin{array}{l}\text { Dimethyl siloxypolyfluoro methyl } \\
\text { siloxypoly(oxyalkylenediyl) methyl siloxy copolymer }\end{array}$ & CBI \\
\hline 18 & P-10-0471 & $\begin{array}{l}\text { Alkyl acrylatepolyfluoro } \\
\text { methacrylatepoly(oxyalkylenediyl)-methacrylates }\end{array}$ & CBI \\
\hline 19 & P-10-0472 & $\begin{array}{l}\text { Alkyl acrylatepolyfluoro } \\
\text { methacrylatepoly(oxyalkylenediyl)-methacrylates }\end{array}$ & CBI \\
\hline 20 & P-10-0485 & $\begin{array}{c}\text { Alkyl methacrylates, polymer with substituted } \\
\text { carbomonocycle, hydroxymethyl acrylamide and } \\
\text { fluorinatedalkyl acrylate }\end{array}$ & CBI \\
\hline 21 & P-10-0546 & Modified lithium iron phosphates & CBI \\
\hline 22 & P-11-0048 & $\begin{array}{c}\text { Diethylene glycol, polymer with diisocyanatoalkane, } \\
\text { polyethylene glycol monomethyl ether- and } \\
\text { fluorinatedalkanol -blocked }\end{array}$ & CBI \\
\hline
\end{tabular}


Table 1 Chemicals meeting inclusion criteria

\begin{tabular}{|c|c|c|c|}
\hline Number & $\begin{array}{l}\text { Premanufacturing } \\
\text { number }\end{array}$ & Generic name (as given in federal register) & $C A S \#$ \\
\hline 23 & P-11-0063 & Perfluoroalkyl acrylate copolymer & CBI \\
\hline 24 & P-11-0203 & $\begin{array}{l}\text { Perfluoroalkylethyl methacrylate copolymer with } \\
\text { dialkylaminoethylmethacrylate }\end{array}$ & CBI \\
\hline 25 & P-11-0247 & $\begin{array}{l}\text { Perfluoroalkylethyl methacrylate copolymer with } \\
\text { hydroxymethyl acrylamide, vinyl chloride and long chain } \\
\text { fatty alkyl acrylate }\end{array}$ & CBI \\
\hline 26 & P-11-0264 & Brominated polyphenyl ether & CBI \\
\hline 27 & P-11-0384 & Fluorinated alkylsulfonamidol urethane polymer & CBI \\
\hline 28 & P-11-0557 & $\begin{array}{l}\text { 2-Propenoic acid, 2-methyl-, 2-hydroxyethyl ester, } \\
\text { telomers with C18-26-alkyl acrylate, 1-dodecanethiol, } \\
\text { N-(hydroxymethyl)-2-methyl-2-propenamide, } \\
\text { polyfluorooctyl methacrylate and vinylidene chloride, } \\
\text { 2,2'-[1,2-diazenediylbis(1-methylethylidene)bis } \\
\text { [4,5-dihydro-1Himidazole] hydrochloride (1:2)-initiated }\end{array}$ & CBI \\
\hline 29 & P-11-0561 & Tetrafluoroethylene chlorotrifluoroethylene copolymer & CBI \\
\hline 30 & P-11-0646 & Perfluoroalkylethyl methacrylate copolymer & CBI \\
\hline 31 & P-11-0653 & Perfluoroalkylethyl methacrylate copolymer & CBI \\
\hline 32 & P-12-0031 & Modified fluorinated acrylates & CBI \\
\hline 33 & P-99-0848 & $\begin{array}{l}\text { Silicic acid ( } \mathrm{H} 6 \mathrm{SiO} 2 \mathrm{O} 7) \text {, magnesium strontium salt } \\
(1: 1: 2) \text {, dysprosium and europium-doped. }\end{array}$ & CBI \\
\hline
\end{tabular}

\subsection{Information provided to the EPA}

Of the 33 PMN submissions analysed, 23 included physiochemical properties data as part of the PMN submission. Specific analyses of these data could not be carried out, because all PMN submitters sought and received CBI protection. Just over one half, or 17, of the PMN submissions included test data on human and/or environmental effects; 16 submissions did not provide any test data or results. Of the 17 submissions that included human or environmental effects test results, only five provided original study reports. The PMN submissions that included original test reports were submitted by organisations within from Germany, Japan or Switzerland. All other test results were either summaries provided by the PMN submitter (Number $=9$ ) or summaries developed by the EPA (Number $=3$ ).

Some PMN submissions included tests on the PMN substances or analogue substances. A total of 142 test results were reported on or summarised across 30 distinct test types (Table 2). The maximum number of test results provided with a submission was 15; the minimum, 1. No discernible pattern existed as to the tests chosen and included in the PMN submissions by PMN submitters. Only 39\% of the 142 test results stated their analyses complied with any recognised test guidelines or standards. Specific test protocols could not be compared across PMN submissions, because very few of the PMN submissions available to the public included test reports. 
Table 2 Test data provided

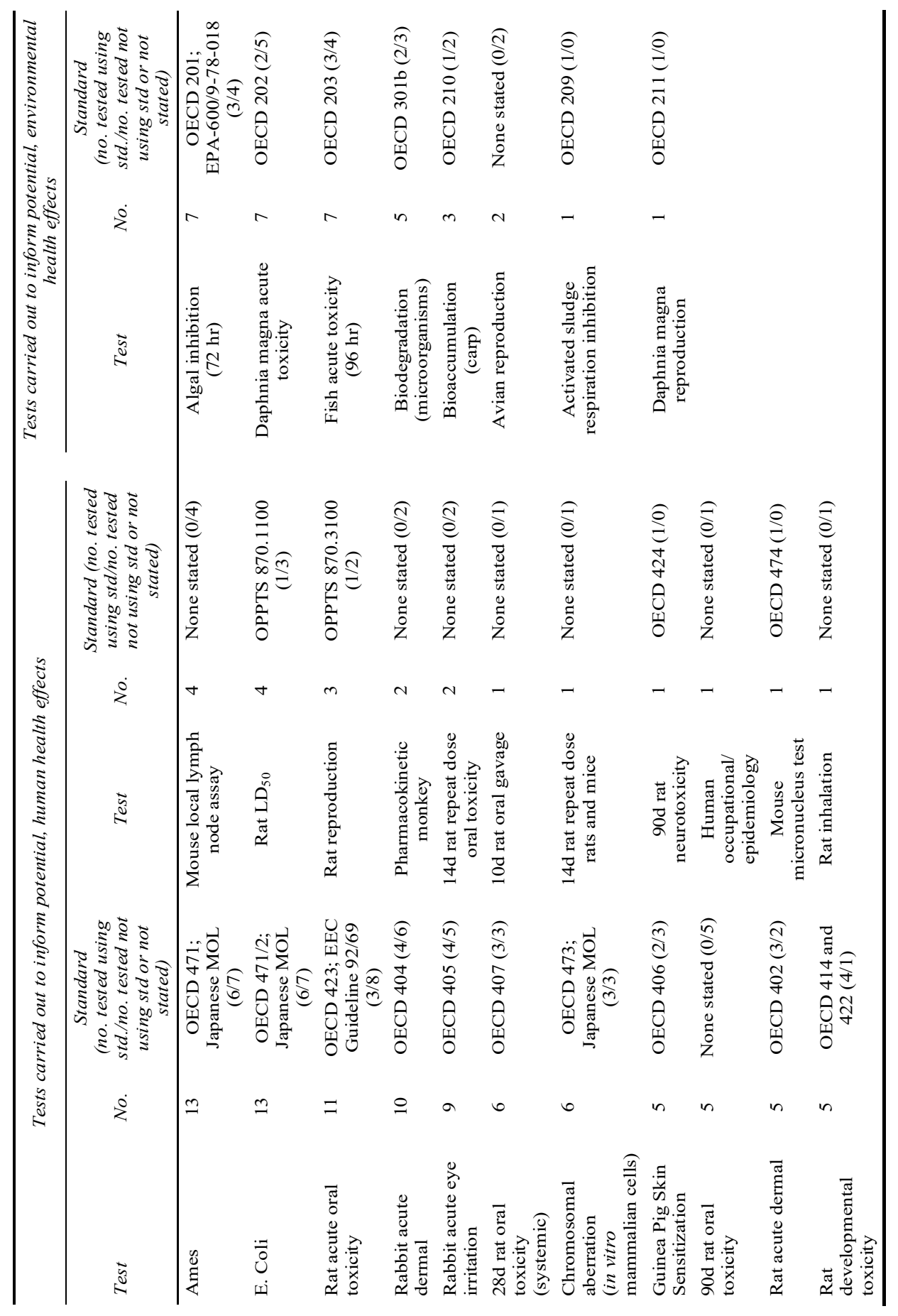




\subsection{Information generated by EPA}

The PMN application process requires the molecular formula, molecular diagram and molecular weight of their PMN substances be provided to the EPA. The EPA uses this information to generate estimates of the PMN substance's physiochemical properties (see Section 2, methods and data). Solubility, boiling point, Henry's law constant and vapour pressure estimates were summarised across the EPAs SAT reports evaluated in this study. The EPA replaced predicted values with actual values in the instances where the PMN submitters provided this information. Actual measurements were redacted by the EPA from the publically available PMN information to comply with CBI claims made by the PMN submitters. Other physiochemical properties estimates were generally not provided within the SAT reports and so could not be analysed.

For some PMN substances, the EPA generated estimates of aquatic toxicity values using SAR (Table 3). Table 3 lists the test organisms evaluated using SAR and the median value across the consent order SAR analyses at which regulation was established. These SAR analyses were carried out using the EcoSAR tool. The EPA replaced predicted values with actual values in the instances where the PMN submitters provided actual test results. The predicted values are presented in the SAT reports. Actual measurements were redacted from the publicly available documents for CBI reasons along with the names of analogue chemicals or other physiochemical values used to arrive at the EcoSAR predictions.

Table 3 EcoTox data generated using EcoSAR

\begin{tabular}{lccc}
\hline Test organism & Test duration $(\mathrm{hr})$ & Endpoint & $\begin{array}{c}\text { Median }(\mathrm{mg} / \mathrm{L}) \text { across } \\
\text { regulated substances }\end{array}$ \\
\hline Fish & 96 & $\mathrm{LC}_{50}$ & 20 \\
Daphnid & 48 & $\mathrm{LC}_{50}$ & 4 \\
Green Algal & 96 & $\mathrm{EC}_{50}$ & 6.95 \\
Daphnid & $\mathrm{N} / \mathrm{A}$ & Chronic value & 3.1 \\
Algal & N/A & Chronic value & 1.1 \\
\hline
\end{tabular}

Finally, the EPA compiled known human health effects information on each PMN substance using the analogue analysis approach (see methods section). Analogue analyses were carried out for every chemical included in this study. The EPA summarised the results of the analogue analyses in the SAT reports, consent orders and Federal Register notices. Analyses were based on analogues of the PMN substances where in vivo information was available. The summaries cited specific health endpoints; however, the identity of the PMN substance was redacted owing to CBI claims. Also redacted was the identity of the analogue substance. Every analysis referenced in vivo studies of analogue substances/classes or to reports on chemical classes of these substances.

\subsection{Data and methods used to inform regulatory decisions}

The majority of the decisions to regulate PMN substances by consent order were based on analogue analyses to determine human health risk. The majority of the regulatory decisions based on environmental risk were supported by SAR (Table 4). Based on the 
information available regarding these 33 PMN substances, the EPA's decisions primarily relied upon the data it generated, supported by analogue analyses.

Table 4 Information/methods applied to inform decisions, including final decisions

\begin{tabular}{|c|c|c|}
\hline Type of information/methods that informed decisions to regulate & \multicolumn{2}{|c|}{ Number } \\
\hline \multicolumn{3}{|l|}{ Human health risk } \\
\hline Analogue search & \multicolumn{2}{|c|}{26} \\
\hline In vivo or in vitro test data submitted by petitioner & \multicolumn{2}{|c|}{12} \\
\hline Other & \multicolumn{2}{|c|}{1} \\
\hline \multicolumn{3}{|l|}{ Environmental health risk } \\
\hline Structure activity relationship (aquatic toxicity) & \multicolumn{2}{|c|}{30} \\
\hline $\begin{array}{l}\text { Basis for consent order decision (unreasonable risk } \\
\text { of injury to health or the environment) }\end{array}$ & Number & $\begin{array}{c}>1 \text { human } \\
\text { health } \\
\text { concern }\end{array}$ \\
\hline Human health & 3 & 3 \\
\hline Environmental health & 5 & $\mathrm{~N} / \mathrm{A}$ \\
\hline Both human and environmental health & 25 & 22 \\
\hline
\end{tabular}

There were nine instances in which ecological toxicity data was provided by the PMN submitter. These data replaced the EcoSAR estimates and served to inform the regulatory decisions based on unreasonable risk to the environment. The EPA published aquatic toxicity values in 15 of the 33 regulated PMN substances (Table 3). A total of eight of 15 chemicals were also determined by the EPA to be persistent or to bioaccumulate. There were no EcoSAR data published in these eight instances. All eight instances were either PFOSs or PFOAs. The remaining ten PMN substances regulated in part owing to environmental health concerns did not include EcoSAR data summarised and were also not identified as persistent or to bioaccumulate. In these ten cases, this study could not determine how EPA made its regulatory decisions or its support for its determination of unreasonable environmental risk.

In 12 instances of determining unreasonable human health risk, or just one third of the time, test data submitted by the PMN submitter primarily informed the decision. In all other decisions based on human health risk, or two thirds of the decisions, analogue analyses were the primary information source underlying the regulatory decision. There were a median number of four human health concerns identified by the EPA per PMN submission. The maximum number of health concerns cited by the EPA for an individual PMN substance was 12; the minimum, three. Risk of pulmonary toxicity was most common, followed by reproductive and developmental toxicity (Table 5). In contrast, tests carried out by PMN submitters rarely tested, or provided data about pulmonary, reproductive or developmental toxicity (Table 2 ).

Finally, in 25 instances, or $76 \%$ of the time, the EPA issued consent orders on the basis that the substance may present an unreasonable risk both to human health and the environment. Of the 33 consent orders issued, a total of 31 significant new use rules (SNUR) was also issued (data not shown). 
Table 5 Human health concerns identified in EPA SAT reports

\begin{tabular}{lc}
\hline Health concern & No. \\
\hline Pulmonary toxicity & 18 \\
Developmental toxicity & 17 \\
Reproductive toxicity & 17 \\
Immuno toxicity & 13 \\
Liver toxicity & 12 \\
Blood toxicity & 10 \\
Dermal sensitisation & 8 \\
Eye irritation & 6 \\
Respiratory sensitisation & 4 \\
Kidney toxicity & 4 \\
Neurotoxicity & 2 \\
Bone marrow toxicity & 1 \\
Spleen toxicity & 1 \\
Thymus toxicity & 1 \\
Thyroid toxicity & 1 \\
\hline
\end{tabular}

\section{Discussion}

The majority of the decisions to regulate PMN substances by consent order were based on analogue analyses to determine human health risk. The majority of the regulatory decisions based on environmental risk were supported by SAR (Table 4). These study findings support the conclusion that the EPA primarily relied upon the data it generated in silico along with existing data analysed using the analogue analysis methodology to arrive at the 33 regulatory decisions. In two thirds of these regulatory decisions, no new in vivo or in vitro tests were carried out to inform these regulatory decisions. This finding is consistent with a prior statement by the EPA that for the New Chemicals Review process the EPA for the most part it is unable to reach decisions based on the submitted data alone (Environmental Protection Agency, 1997).

The data and methods applied by the EPA to inform decisions further represent distinct types of alternative testing and alternative methods. Alternative test methods are those approaches that reduce, refine or replace in vivo tests (ICCVAM, 2000). The creation and adoption of alternative test methods are important for ethical, cost and efficiency reasons. First, the ethical treatment of animals is culturally important in Western society and the public is increasingly scrutinising the use of animals in testing. Second, it is generally accepted that alternative methods can potentially result in significant cost savings over traditional, in vivo methods (van Der et al., 2004). Finally, alternative methods can be carried out more quickly and the same test can be carried out on a multitude of chemicals simultaneously (Judson et al., 2010). TSCA requires evaluation of PMN submissions within 90 days, necessitating the use of methods like analogue analysis and in silico, so that information can be quickly generated to inform decisions. TSCAs New Chemicals Program has, by necessity, developed and made use of 
these alternative methods, demonstrating that laws can promote innovation and efficiencies.

TSCA is not the only law to encourage such innovation. An ad hoc group of experts on behalf of the European Commission (2003) reviewed the state of the art of safety assessment by animal and non-animal tests for 11 different human health effects of concern in the frame of the seventh amendment of the Cosmetics Directive 76/768/EEC, aiming at establishing time tables for the implementation of marketing and testing bans including deadlines for the phasing out of the various animal tests, which has been carried out (European Union, 2003). Such a strategy is consistent with the National Academies vision of toxicity testing in the 21 st century to use alternative methods more extensively, with much reduced need for whole animal testing (NRC, 2007).

This study was able to evaluate only 33 consent order decisions, and its conclusions and analyses are bounded by this limited sample size. Sample size was restricted for two reasons. First, most PMN submitters classify their submissions as CBI and seek broad exclusion of information from the public, including: the substance itself, the company name, where the chemical is made, what the production volume is, what the intended uses are, etc. Second, the documents supporting publicly available consent order decisions has become available electronically only in the past decade. Given these facts, it is not possible to assess whether the 33 chemicals evaluated in this study are representative of the universe of chemicals that have undergone PMN review. However, personal conversation with an official at the EPA indicated that analogue and SAR analyses are commonly used to evaluate PMN substances (personal communication, Dr. Louis Scarano, 28 February 2014), which supports the major findings of this study. The consent orders evaluated in this study were issued from 1999 to 2012 and so study results likely represent current patterns of analyses and decision making.

It is revealing that the TSCA Chemical Substance Inventory lists only 266 chemicals that are subject to consent order. However, in EPAs Summary of Accomplishments dated September 30, 2010, a total of 1,492 chemicals are stated to be subject to consent order (Environmental Protection Agency, 2014). Apparently, only 18\% of the chemicals regulated by consent order are identified as such to the public on the TSCA Chemical Substance Inventory. It appears that the majority of chemicals on the TSCA Chemical Substance Inventory identified as a human or environmental health concern are not readily identifiable to the public. It seems that this lack of transparency is due to CBI claims, which limit information release on the TSCA Chemical Substance Inventory.

The results of this study further demonstrate that regulatory agencies like EPA can face challenging situations in which they must render decisions within specific, legal constraints. The TSCA New Chemicals Program does not require PMN submitters to generate and submit health and/or environmental effects data. The EPA does not have legal authority to require testing and cannot require submission of previous testing. Only half of the PMN submissions evaluated in this study provided test data. Further, the tests carried out by PMN submitters are generally not aligned with the health endpoints of concern that the EPA identified with the PMN substances. For instance, the three most cited human health endpoints across the PMN substances evaluated in this study were pulmonary toxicity, reproductive toxicity and developmental toxicity. In contrast, the PMN submissions carried out only one pulmonary toxicity study. Only three reproductive toxicity studies and five developmental toxicity studies were carried out. We reason that this represents a gap in industry studies, likely due to the high costs and time required to 
conduct these study types. This also represents a gap in EPA's present alternative testing capabilities that cannot compensate for the lack of data provided by industry. These three health concerns can be a priority for industry and EPA to collaborate, evaluate, validate and adopt alternative testing strategies that specifically evaluate these recurring human health concerns.

In closing, the primary finding of this study is that the majority of the EPA's New Chemicals Program decisions to regulate by consent order were based on analogue analyses and SAR (Table 4). Analogue analyses were the tool of choice to support regulatory decisions based on human health endpoints. SAR supported regulatory decisions based on environmental (ecological) endpoints. In two thirds of these decisions to regulate, no new in vivo or in vitro tests were carried out to inform these regulatory decisions. This is the first study to evaluate the methods and strategies used to inform TSCAs New Chemicals Program decisions to regulate via consent order. We reason that this study and its findings will be useful to regulators in situations in which data availability is constrained by law. In addition, the analysis provided here shows that the adoption of alternative testing methods can be successful in informing and therefore supporting regulatory decisions.

\section{References}

Auer, D.M., Nabhold, J.V. and Baetcke, K.P. (1990) 'Mode of action and the assessment of chemical hazards in the presence of limited data: use of structureactivity relationships (SAR) under TSCA, section 5', Environmental Health Perspectives, Vol. 87, pp.183-197.

Barry, V., Winquist, A. and Steenland, K. (2013) 'Perfluorooctanoic acid (PFOA) exposures and incident cancers among adults living near a chemical plant', Environmental Health Perspectives, Vol. 121, Nos. 11/12, pp.1313-1318.

Benbrahim-Tallaa, L., Lauby-Secretan, B., Loomis, D., Guyton, K.Z., Grosse, Y., El Ghissassi, F., Bouvard, V., Guha, N., Mattock, H., Straif, K. and International Agency for Research on Cancer Monograph Working Group (2014) 'Carcinogenicity of perfluorooctanoic acid, tetrafluoroethylene, dichloromethane, 1,2-dichloropropane, and 1,3-propane sultone', Lancet Oncology, Vol. 15, No. 9, pp.924-925.

Boethling, R.S., Howard, P.H. and Meylan, W.M. (2004) 'Finding and estimating chemical property data for environmental assessment', Environment Toxicology and Chemistry, Vol. 23, No. 10, pp.2290-2308.

Environmental Protection Agency (1994) US EPA/EC Joint Project on the Evaluation of (Quantitative) Structure Activity Relationships, EPA 743-R-94-0001, Office of Prevention Pesticides and Toxic Substances, Washington, DC [online] http://www.epa.gov/oppt/newchems/pubs/ene4147.pdf (accessed 14 September 2015).

Environmental Protection Agency (1997) Chemistry Assistance Manual for Premanufacture Notification Submitters: 1997, EPA 744-R-97-003, Office of Pollution Prevention and Toxics, United States Environmental Protection Agency, Washington, DC [online] http://www.epa.gov/oppt/newchems/pubs/chem-pmn/index.htm (accessed 14 September 2015).

Environmental Protection Agency (2007) Science Advisory Board (SAB) review of the Estimation Programs Interface Suite (Epi Suite), EPA-SAB-07-11, Science Advisory Board, US Environmental Protection Agency, Washington, DC [online] http://yosemite.epa.gov/sab/sabproduct.nsf/0/cacf0e5697d205f685256d4a004a47fa!Op enDocument\&TableRow=2.3 (accessed 14 September 2015).

Environmental Protection Agency (2014) New Chemicals - New Chemicals Program, Summary of accomplishments [online] http://www.epa.gov/opptintr/newchems/pubs/accomplishments.htm (accessed 14 September 2015). 
EUROPA (2006) 'Regulation (EC) No. 1907/2006 of the European Parliament and of the Council concerning the registration, evaluation, authorisation and restriction of chemicals', Official Journal of the European Union [online] http://eur19lex.europa.eu/legal-content/ EN/TXT/?uri=CELEX:02006R1907-20140410 (accessed 14 September 2015).

European Commission (2003) Technical Guidance Document on Risk Assessment, EUR 20418 EN/2, 2003, Joint Research Centre, Ispra [online] https:/echa.europa.eu/documents/ 10162/16960216/tgdpart2_2ed_en.pdf (accessed 14 September 2015).

European Union (2003) 'Directive 2003/15/EC of the European Parliament and of the Council', Official Journal of the European Union, Vol. 66, pp.26-35 [online] http://eurlex.europa.eu/ LexUriServ/LexUriServ.do?uri=OJ:L:2003:066:0026:0035:en:PDF (accessed 14 September 2015).

Executive Order 12866 of September 30 (1993) Regulatory Planning and Review, Federal Register, 58: 190, Washington, DC [online] https://www.whitehouse.gov/sites/default/files/omb/ inforeg/eo12866/eo12866_10041 993.pdf (accessed 14 September 2015).

Federal Register Act (1935) Washington, DC [online] http://www.llsdc.org/assets/sourcebook/ pl74-220-lh.pdf (accessed 14 September 2015).

Interagency Coordinating Committee on the Validation of Alternative Methods (ICCVAM) (2000) ICCVAM Authorization Act of 2000, Washington, DC [online] https://history.nih.gov/research/ downloads/PL106-545.pdf (accessed 14 September 2015).

Judson, R.S., Houch, K.A., Kavlock, R.J., Knudsen, T.B., Martin, M.T., Mortensen, H.M., Reif, D.M., Rotroff, D.M., Shah, I., Richard, A.M., and Dix, D.J. (2010) 'In vitro screening of environmental chemicals for targeted testing prioritization: the ToxCast project', Environmental Health Perspectives, Vol. 118, No. 4, pp.485-492.

Nakayama, S., Haradak, K., Inoue, K., Sasaki, K., Seery, B., Saito, N., and Koizumi, A. (2005) 'Distributions of perfluorooctanoic acid (PFOA) and perfluorooctane sulfonate (PFOS) in Japan and their toxicities', Environmental Sciences, Vol. 12, No. 6, pp.293-313.

National Research Council (NRC) (2007) Toxicity Testing in the 21st Century: A Vision and a Strategy, National Academies Press, Washington, DC [online] http://www.nap.edu/openbook.php?record_id=11970 (accessed 14 September 2015).

Reuschenbach, P., Silvani, M., Dammann, M., Warnecke, D., and Knacker, T. (2008) 'ECOSAR model performance with a large test set of industrial chemicals', Chemosphere, Vol. 71, No. 10, pp.1986-1995.

Toxic Substances Control Act (TSCA) (1976) Washington, DC [online] http://www.gpo.gov/ fdsys/granule/CFR-2011-title40-vol31/CFR-2011-title40-vol31-chapI-subchapR/ content-detail.html (accessed 14 September 2015).

US Government Publishing Office (2011) Part 720-Premanufacture Notification, 40 Code of Federal Regulations, pp.127-155, Washington, DC [online] http://www.gpo.gov/fdsys/ granule/CFR-2011-title40-vol31/CFR-2011-title40-vol31-part720 (accessed 14 September 2015).

van Der, J.K., Munn, S.J., Torslov, J. and de Bruijn, J. (2004) Alternative Approaches Can Reduce the Use of Test Animals Under REACH, European Commission, Directorate General, Joint Research Centre, Institute for Health and Consumer Protection [online] http://publications.jrc.ec.europa.eu/repository/handle/JRC29111 (accessed 14 September 2015).

Walker, J.D. (2003) 'Applications of QSARs in toxicology: a US Government perspective', J. Molecular Structure, Vol. 622, Nos. 1/2, pp.167-184. 